\title{
A EJA em contextos de privação de liberdade: desafios e brechas à Educação Popular
}

\author{
EJA in contexts of deprivation of freedom: \\ challenges and gaps to Popular Education
}

\section{La EJA en contexto de privación de libertad: desafíos y brechas en la Educación Popular}

\author{
Elenice Maria CAMmarosano ONOFRE ${ }^{10}{ }^{1}$ \\ JARINA RODRIGUES FERNANDES ${ }^{1}{ }^{1}$ \\ ANA Claudia FERREIRA GODINHO ${ }^{2}{ }^{2}$ \\ ${ }^{1}$ Universidade Federal de São Carlos, São Carlos, São Paulo, Brasil.
}

${ }^{2}$ Universidade Federal do Rio Grande do Sul, Porto Alegre, RS, Brasil. \begin{abstract}
$\diamond$
\section{RESUMO}

O ensaio discute a Educação de Jovens e Adultos em privação de liberdade na perspectiva da Educação Popular. Apresenta dados estatísticos do sistema prisional brasileiro, reflexões sobre o papel da escola e a pertinência do diálogo entre educação escolar e não escolar nos espaços de privação de liberdade. Sugere brechas e possibilidades para a educação nos referidos espaços a partir de três dimensões: a articulação entre as práticas educativas propostas; a organização curricular flexível; e o trabalho interdisciplinar como proposta metodológica, e a valorização do trabalho docente, com a indicação de que, justamente a partir das situações-limite, é possível potencializar a dimensão política das práticas sociais vinculadas à educação nas prisões.
\end{abstract}

Palavras-chave: Educação na prisão. Educação de Jovens e Adultos. Educação Popular. Práticas educativas na prisão.

\section{Abstract}

This essay discusses the Education of Youth and Adults in deprivation of liberty from the perspective of Popular Education. It presents statistical data on the Brazilian prison system, reflections on the role of the school and the relevance of the dialogue between school and non-school education in places of deprivation of liberty. It suggests gaps and possibilities for education in these spaces, from three dimensions: the articulation between the proposed educational practices; the flexible curricular organization and the interdisciplinary work as a methodological proposal and the valorization of teaching work, with the indication that, precisely, from the limit situations, it is possible to enhance the political dimension of social practices linked to education in prisons.

Keywords: Education in prison. Youth and Adult Education. Popular Education. Educational practices in prison.

\section{RESUMEN}

El ensayo discute la Educación de Jóvenes y Adultos en privación de libertad en la perspectiva de la Educación Popular. Presenta datos estadísticos del sistema carcelario brasilero, reflexiones sobre el papel de la escuela y la pertinencia del diálogo entre educación escolar y no escolar en los espacios de privación de libertad. Sugiere brechas y posibilidades para la educación en los referidos espacios, a partir de tres dimensiones: la articulación entre prácticas educativas propuestas; la organización curricular flexible y el trabajo interdisciplinar como propuesta metodológica y la valoración del trabajo docente, con la indicación de que, justamente, a partir de las situaciones límite, es posible potenciar la dimensión política de las prácticas sociales vinculadas a la educación en las cárceles.

Palabras clave: Educación en la prisión. Educación de Jóvenes y Adultos. Educación Popular. Prácticas educativas en la prisión. 


\section{Apresentando o ensaio}

\author{
"Todo o saber, só é saber \\ porque constrói uma ação”. \\ (Petronilha Beatriz Gonçalves e Silva, 1987)
}

$\mathrm{O}$ ensaio que se apresenta é fruto da confluência de estudos no campo da educação escolar em espaços de restrição e privação de liberdade, em diálogo com nossas trajetórias, como pesquisadoras dedicadas a compreender as complexas dinâmicas desses espaços e como formadoras de professores, gestores e agentes prisionais que atuam nesses contextos. Os estudos, as pesquisas e as vivências decorrentes do desenvolvimento de projetos de extensão - desde a participação em rodas de leitura, a cursos de pequena duração para as pessoas aprisionadas - nos permitem tecer reflexões e sínteses analíticas. Por outro lado, os cursos de formação ministrados ao longo dos anos para professores, gestores educacionais e agentes prisionais, ao lado dos estudos teóricos, encontros acadêmicos, rodas de conversas reflexivas e pesquisas, foram se constituindo em um corpo de saberes que desejamos compartilhar na perspectiva indicada na epígrafe - os saberes são construídos por/para uma ação.

Neste escrito temos como proposta reafirmar a nossa postura, que opta por uma educação libertadora nos espaços de privação de liberdade e se pretende ir além de transportar para o interior dessas escolas conhecimentos construídos por e para homens livres. A intenção é provocar um processo de organização do conhecimento em uma dimensão diferente, de temáticas significativas para homens e mulheres afastados por algum tempo do mundo doméstico e que ali precisam sobreviver. Trata-se do pensar situado, que na perspectiva de Freire "não está fora dos homens, nem num homem só, nem no vazio, mas entre os homens, e sempre referido a uma realidade" (1993, p. 117).

O texto encontra-se organizado em quatro seções. Inicialmente, apresentamos dados estatísticos que permitem visualizar a dimensão do desafio que se apresenta. Em um segundo momento, destacamos concepções fundamentadas na educação popular, a partir das quais compreendemos a educação em espaços de privação de liberdade. Na terceira seção, nos debruçamos sobre o papel da escola, que se insere no espaço da prisão. A quarta seção aborda as brechas e possibilidades para a educação nas prisões. Por fim, nas considerações finais, ao problematizar situações presentes no contexto das prisões, vislumbramos pistas, com a indicação de que justamente a partir das situações-limite deveríamos potencializar a dimensão política das práticas sociais vinculadas à educação.

\section{O CONTEXTO DE PRIVAÇÃO DE LIBERDADE NO BRASIL: ENCARCERAMENTO EM MASSA E NEGLIGÊNCIA DO DIREITO À EDUCAÇÃO PELO ESTAdo}

Para refletir sobre a educação em contextos de privação de liberdade, é importante considerar as condições em que se encontra o sistema prisional brasileiro, haja vista que ele é o retrato do modo como o Estado lida com a população privada de liberdade no País. Nesse sentido, conhecer o perfil da população prisional brasileira nos permite compreender quem o Estado brasileiro encarcera, assim como conhecer as condições do sistema prisional nos indica o quê, efetivamente, o Estado tem estabelecido como função social da prisão.

Segundo dados de 2016 do Infopen - Levantamento Nacional de Informações Penitenciárias (DEPARTAMENTO PENITENCIÁRIO NACIONAL, 2017), o Brasil hoje tem a 3 a maior população prisional do mundo, com 726.712 mil pessoas, perdendo apenas para os Estados Unidos e a China. No que concerne à taxa de aprisionamento, o Brasil também está nas primeiras posições no ranking mundial, com 352,6 mil presos por 100 mil habitantes.

Esses dados evidenciam o elevado número de pessoas encarceradas no País, o que é preocupante se considerarmos toda a estigmatização e exclusão social decorrentes de uma passagem pela prisão. No entanto, se compararmos esses dados com a população prisional dos anos anteriores, veremos que a situação é ainda mais grave. Dez anos antes, em 2006, a população prisional era de 401 mil; recuando mais uma década, no ano de 1997 (pois em 1996 o Ministério da Justiça não divulgou o dado) a população prisional era de 170,6 mil. Em outras palavras, a população prisional brasileira quadruplicou em vinte anos. Embora a população prisional feminina seja reduzida, em comparação à masculina, o encarceramento de mulheres é também um tema preocupante, pois o seu crescimento foi de $567 \%$ entre 2000 e 2016.

$\mathrm{O}$ aumento da população prisional no Brasil não foi acompanhado pelo crescimento de vagas, que é de 376 mil. Sendo assim, o encarceramento em massa vem ocasionando um problema de superlotação das unidades prisionais, com uma taxa de ocupação de 197,4\% (BRASIL, 2017). A superlotação desencadeia uma série de problemas quanto à assistência à pessoa privada de liberdade, garantida como direito pela Lei de Execução Penal - LEP (BRASIL, 1984) -, a começar pela assistência jurídica: no ano de 2016 as pessoas que se encontravam privadas de liberdade sem condenação representavam $40 \%$ da população prisional brasileira. Todas as outras assistências - de saúde, educacional etc. - ficam comprometidas também, afinal, a equipe de técnicos e educadores é contratada ou nomeada para 
atender o número de apenados ou apenadas que a unidade prisional deveria atender, e não a que efetivamente atende.

Entendemos, por esses dados, que o Brasil está passando por um processo de encarceramento em massa similar ao que vem sendo denunciado por sociólogos e criminologistas estadunidenses em relação ao seu país, como Wacquant (2011). Esse autor analisa a realidade dos Estados Unidos desde a implementação do modelo conhecido como "Tolerância Zero", que acirrou as políticas de controle e criminalização dos pobres, sobretudo da população negra - justamente os mais desassistidos pelos cortes de políticas sociais desde os anos 1970. Ainda que analise o contexto de outro país, a análise do autor é pertinente para compreendermos o acirramento das políticas penais justamente no momento de consolidação de políticas neoliberais, que precarizam as relações de trabalho e acentuam os níveis de desemprego e trabalho informal em muitos países, inclusive no Brasil.

Nesta conjuntura de encarceramento em massa e superlotação das unidades prisionais, quem são as pessoas privadas de liberdade no Brasil? Com base nos dados do Infopen referentes a 2016 (BRASIL, 2017), podemos afirmar que o Estado brasileiro tem um alvo bem definido para a prisão: os jovens, negros, pobres, com baixa escolaridade. Para compreender essa afirmação, basta observar os dados: no que diz respeito à faixa etária da população prisional, 54\% têm idade entre 19 e 29 anos; dos 726.712 mil presos, $67 \%$ são pessoas negras; $31 \%$ são pessoas brancas; e mais de $90 \%$ fazem parte da população prisional masculina.

O nível de escolaridade da população prisional explicita a violação do direito à educação como um ponto em comum entre os apenados brasileiros: $53 \%$ têm Ensino Fundamental incompleto e 41\% têm Ensino Médio incompleto. Ou seja, $94 \%$ da população não têm o Ensino Médio completo, nível de escolaridade definido pelo Artigo 205 da Constituição Federal de 1988 como direito subjetivo de todo cidadão e cidadã brasileira, independentemente de idade, raça, gênero ou credo religioso. Apesar da demanda escolar de quase toda a população prisional, o acesso a atividades educacionais é de somente $13 \%$ (BRASIL, 2017). Portanto, dentro da prisão esses jovens negros das classes populares experimentam a mesma negligência do Estado em relação ao direito à educação que já conheceram no contexto extramuros, em sua infância e adolescência. É nesse contexto que pensamos na educação de jovens e adultos na perspectiva da educação popular.

\section{A educação popular vai à prisão}

Aparentemente é um contrassenso que uma prática social voltada para a liberdade e a emancipação humana
- a educação - aconteça dentro de uma instituição social criada justamente para retirar do ser humano a sua liberdade e a sua autonomia. Como uma instituição que aprisiona poderia promover a liberdade? A prisão caracterizada por Goffman (2015) como instituição total por seus rígidos e minuciosos processos de destituição da identidade, desde o ingresso na unidade, e por um sistema de privilégios baseado na obediência e na submissão a relações de poder arbitrárias e autoritárias - poderia ser, contraditoriamente, um espaço de questionamento, reflexão e, portanto, leitura crítica do mundo?

Em nossas reflexões sobre o tema, temos argumentado que sim, é possível encontrar, no cotidiano das unidades prisionais, brechas ou fissuras nessa estrutura hierárquica e autoritária. Além disso, entendemos que esse paradoxo faz parte das especificidades da educação de jovens e adultos em contextos de restrição e privação de liberdade. Se lidar com as contradições do contexto é um desafio que a educação popular nunca se negou a enfrentar, na prisão não seria diferente.

A educação popular, desde as experiências desenvolvidas por Paulo Freire e outros educadores do final dos anos 1950, até o golpe de 1964, sempre buscou conhecer e valorizar as culturas e os saberes populares como expressões do protagonismo das classes populares na produção da Cultura, da História, da Arte e da Ciência. Distantes da erudição, da formalidade ou da normatização das instituições sociais legitimadas como espaços de produção de conhecimento, os saberes populares foram compreendidos pela educação popular como expressões legítimas de um saber indissociável da experiência humana, e essa, por sua vez, está ligada às condições de classe, gênero e raça dos sujeitos que vivem essa experiência.

Nesse sentido, o modo de olhar, escutar e interpretar as palavras dos sujeitos da educação busca conhecer o Outro, reconhecendo-o como um sujeito com experiências e saberes produzidos nas mais diversas esferas da vida. Se considerado o sujeito da educação em contextos de privação de liberdade, esse aspecto é ainda mais importante, haja vista que a pessoa privada de liberdade é estereotipada como perigosa, agressiva, traiçoeira e, portanto, indigna de confiança. Esse estereótipo está presente dentro e fora da prisão, e a sua desnaturalização é um dos desafios da educação popular.

O que pode fazer, então, a educação popular em contextos de restrição e privação de liberdade? Diante de um contexto de encarceramento em massa e criminalização da juventude brasileira pobre e negra, assumir o compromisso ético e político da educação como prática social voltada para a liberdade e o protagonismo do ser humano na produção da sua existência individual e coletiva, como nos ensinou Freire (2005), é um modo de 
contribuir para que os educandos se vejam como sujeitos de direitos. Independentemente de estarem privados do direito de ir e vir em cumprimento de pena ou de medida socioeducativa, essas pessoas são cidadãs com direitos assegurados pela legislação. $\mathrm{O}$ aprisionamento é uma condição de vida provisória, e ao retornar para o convívio social essas pessoas podem estar em condições de retomar ou recriar os seus projetos de vida de acordo com as experiências que tenham acumulado na prisão. Nossa aposta é que essas experiências venham de processos educativos escolares e não escolares baseados no desenvolvimento do letramento, na elevação de escolaridade, na qualificação e educação profissional, na participação em atividades culturais, esportivas e de lazer, entre outras. Ou seja, que a prisão seja um lugar de acesso a direitos humanos negados ao longo das histórias de vida desses homens e mulheres e, desse modo, contribua para que essas pessoas retomem o convívio social com melhores condições de produção da existência do que as anteriores à privação de liberdade.

A privação de liberdade não os destitui de sua humanidade, por mais que a prisão seja um espaço repleto de processos de desumanização - a começar pela superlotação e a decorrente precariedade dos atendimentos de saúde, educacional, psicológico e assistencial. A prisão produz cotidianamente processos de destituição da identidade pessoal dos detentos, definidos por Goffman (2015) como a mortificação do eu. Para o autor, desde a admissão na instituição total, o indivíduo passa por uma série de situações que visam retirar dele qualquer traço de sua personalidade para moldar uma nova identidade, afinada com as normas da própria instituição, que se baseiam em um sistema hierárquico rígido, repleto de arbitrariedades e abuso de poder.

$\mathrm{Na}$ educação popular, portanto, esses sujeitos podem encontrar um contraponto importante aos processos de destituição da sua identidade. Ao protagonizarem uma prática social que afirma identidades positivas e cria projetos de vida que resgatam sonhos, esperanças, talentos e habilidades, os educandos e educandas reconhecem-se como sujeitos com experiências e saberes positivos, que não produziram somente crime e violência, pessoas que não se reduzem ao artigo do código criminal que os levou à prisão.

Diante disso, a educação popular é muito potente, no sentido de contribuir para que esses sujeitos façam a leitura crítica (FREIRE, 2005) do contexto socio-histórico e cultural em que vivem.

\section{A ESCOLA VAI À PRISÃo}

A escola que vai à prisão é, antes de tudo, escola. Não uma escola da prisão, mas a escola no espaço prisional (ONOFRE, 2011; 2016). “O que é?", "por quê?” e "para que uma escola se destina?" são perguntas importantes, pois as especificidades do contexto prisional podem gerar compreensões equivocadas dessa instituição. A escola em quaisquer espaços é uma instituição secular destinada a promover a socialização e preparar os educandos para a sua inserção na sociedade. O uso da escola pelas classes dominantes para reproduzir o status quo não depõe contra o seu potencial transformador. Aliás, é justamente porque a escola é capaz de atuar como alavanca de transformação social (FREIRE, 1991) que é tão alvejada por parte daqueles a quem não interessa tal transformação, para fins de seu controle. "Da reprodução à reconstrução crítica do conhecimento e da experiência" (PÉREZ GÓMEZ, 2000, p. 13), lá está a escola. Lá está a escola na prisão.

Estamos de acordo que a escola não pode abrir mão de seu papel de democratização do conhecimento, historicamente construído a fim de oportunizar às classes populares apropriar-se de conteúdos e instrumentos necessários a sua emancipação (SAVIANI, 1999). Confirmamos também que cabe à escola promover situações que favoreçam aos educandos aprenderem a realizar "combinações pessoais de conhecimentos, habilidades, emoções, atitudes e valores" capazes de orientar "a interpretação, a tomada de decisões e atuação dos indivíduos humanos em suas interações com o cenário em que habitam, tanto na vida pessoal e social" (PÉREZ GÓMEZ, 2015, p. 75).

A privação de liberdade carrega situações-limite para o espaço da escola, da aula. Como educar para a autonomia e para a criticidade aqueles que sequer são autorizados a levantar a cabeça para caminhar e, por vezes, são proibidos de olhar nos olhos dos educadores? Importante destacar que existem dois grupos de aprendizagens próprios das prisões: as regras oficiais (da instituição) e as regras não oficiais (dos próprios presos). Como sinaliza De Maeyer (2013), na prisão os sujeitos aprenderão coisas novas e terão deixado de praticar uma porção de responsabilidades que serão exigidas no retorno ao convívio social:

[...] as refeições são fornecidas; eles não precisam fazer compras, gerir o dinheiro, preparar, nem lavar a louça; - aprende-se a obedecer sem muito questionar o porquê e não se toma nenhuma iniciativa que possa bagunçar o ambiente. Após ter sido um mau cidadão, vai-se tornar um bom prisioneiro; - vive-se sem dinheiro, sem pensar na moradia e em sua manutenção. O horário é repetitivo, os dias são iguais; - aprende-se a trabalhar por um salário que não é um; - aprendese a perder sua intimidade, a viver em um mundo não misto, sem relações afetivas - ou muito pouco afetiva; - aprende-se a repetir. Tudo isso é a educação da prisão, não a educação na prisão! É neste contexto que começa o trabalho dos educadores (DE MAEYER, 2013, p. 41-42). 
A defesa do direito dos que se encontram em privação de liberdade não se faz sob uma perspectiva romântica de sua deresponsabilização pelos seus atos (OLIVEIRA JÚNIOR, 2016). Faz-se a partir do entendimento de que se a privação da liberdade é a sentença por um desvio social cometido, devemos recordar que os demais direitos do cidadão estão (por lei) preservados. A mera punição a que serve, para quem, para quê? Tais questões problematizadoras que perpassam a obra freiriana nos ajudam a refletir sobre a finalidade das instituições prisionais. Só haverá possibilidade de que tais instituições sejam educativas se houver oferta de experiências e de aprendizagens que façam sentido para a sua vida no momento da privação de liberdade e no seu retorno ao convívio social.

A escola no contexto prisional há de ser espaço para apreensão, compreensão e significação da realidade, a fim de que os educandos tenham condições de projetar uma nova trajetória no interior dessa realidade e comecem a agir de modo a dar passos rumo ao projeto delineado (COSTA, 2006). Tal postura, indicada pela literatura voltada à educação em espaços de restrição e privação de liberdade, coloca-se em consonância com as indicações de Pérez Gómez (2015), de que a educação na sociedade contemporânea deveria ser capaz de formar pessoas com competência para analisar e compreender as situações problemáticas, elaborar e planejar modos de intervenção; atuar de forma flexível, sensível, criativa e adaptativa e ser capaz de avaliação reflexiva de processos e resultados, bem como a formulação de propostas contínuas de melhoria.

O papel da escola é ser um espaço de linguagens, de arte, de educação do corpo e do movimento, de matemática, de ciências da natureza e da sociedade, de filosofia, de tecnologias, de cultura. É importante considerar que as propostas pedagógicas devem ser capazes de "fazer sentido", criar sentidos nos sujeitos envolvidos, de modo a possibilitar a construção de novos significados diante do mundo, do outro e da sua própria existência. Isso acontece em processos educativos em que os educandos podem ser sujeitos, projetar-se de algum modo, nas atividades pedagógicas propostas. $\mathrm{O}$ que vale a pena conhecer, experimentar, superar e compartilhar? "De que nos servem conhecimentos que não nos ajudem a conhecer-nos?" (ARROYO, 2011, p. 279). A colocação da importância da criação de sentido não se assenta na perspectiva de uma escola que barateie a democratização do conhecimento científico em nome do respeito aos conhecimentos dos educandos, mas de uma escola capaz de dialogar com as suas trajetórias, alavancar avanços, fomentar processos e resultados, de modo que possam vislumbrar outros cenários, novas possibilidades.
As relações sociais que acontecem no seu interior constroem suportes sociais e culturais importantes. A escola, por se constituir, em nosso entender, em uma comunidade, regida por normas diferenciadas é um espaço onde os estudantes podem exercitar a possibilidade da quebra de hierarquias, as relações de respeito e a melhoria da autoestima. Ela tem, portanto, um papel relevante na formação de uma população que vive à margem porque cresceu nas margens de uma sociedade que exclui pobres, negros e analfabetos. São pessoas invisíveis até cometerem algum crime, assim definido pelos grupos sociais aos quais nunca pertenceram. Nossa compreensão é que a prisão, instituição singular porque se propõe punitiva para (re)educar, que encarcera corpos e mentes, guarda na escola as regularidades da Educação de Jovens e Adultos "da rua", embora tenha que se adaptar às regras e normas rígidas da prisão. Estamos, portanto, entre regularidades e singularidades (ONOFRE, 2013). Há algo posto, dado: a restrição ou privação de liberdade diante de um ato em conflito com a lei. Contudo, a margem de liberdade que a escola provoca ao trazer novas oportunidades de ampliação dos horizontes do conhecimento e de projeção de uma vida para além das grades são constatações recorrentes nas pesquisas realizadas junto àqueles que frequentam a escola no espaço prisional (CAMPOS, 2015; DUARTE, 2017).

A luta pela presença da escola no espaço prisional deveria ser batalha já vencida. Entretanto, ainda é pauta urgente a questão do (des)atedimento das demandas, assim como ainda urge reivindicar condições para uma educação de qualidade nas prisões onde as salas de aula já existem. Como aponta De Maeyer (2013), não podemos nos conformar com uma educação de segunda para pessoas de segunda. A Educação de Jovens e Adultos, a EJA no contexto prisional, não pode ser "uma distribuidora" de conhecimentos básicos com vistas à certificação, como novas roupagens para a Educação Bancária (FREIRE, 1993). Um currículo que prescreve um "mínimo" que é o "máximo" para salvaguardar o discurso do direito é um currículo traiçoeiro que oferece migalhas para cumprir minimamente a legislação.

Isso posto, caminhamos para o nosso desafio: estamos diante de duas instituições em pleno movimento de funcionamento: a prisão e a escola - uma se (re) fazendo dentro da outra. Em meio a tantos protocolos de segurança, típicos de uma unidade prisional, como organizar as práticas pedagógicas para a escola?

Existem boas práticas desenvolvidas em diversos pontos do País; as dissertações e teses voltadas para o campo pedagógico em contextos de privação de liberdade têm crescido nos últimos anos. Trabalhos como os de Santana (2013), Pessano, (2015), Marques (2016), Silva (2017), Scholz (2017) e Silva (2019), apontam a 
pertinência do diálogo, de práticas interdisciplinares e metodologias ativas, que procuram partir da condição dos educandos, de sua trajetória, conhecimentos e sentidos, para a criação de novos sentidos e significados. Chama atenção a criatividade na busca de materiais pedagógicos que possam ser utilizados em contexto prisional e o desejo de educandos e de educadores de construírem algo novo, no tempo e no espaço concedidos à escola no contexto prisional: a aula.

Ainda que a legislação que prescreve a obrigatoriedade da educação escolar nos espaços de privação de liberdade seja uma importante conquista (BRASIL/ CNE/CEB, 2010; BRASIL, 2011), a educação escolar nas prisões tem sofrido para sobreviver, diante da descontinuidade dos apoios locais e a depender das tendências políticas de governo. Ora, se estamos em um espaço que, pretensamente, deve devolver à sociedade sujeitos com melhor condição para o convívio social, se nesses espaços existe uma escola pública, uma sala de aula (mesmo que improvisada, com turmas heterogêneas, multisseriadas, como tantas outras no Brasil), professores (com salários aviltantes, ausência de material didático e outras ferramentas para um trabalho com qualidade social, formação insuficiente para atuar em Educação de Jovens e Adultos) e estudantes (advindos em sua maioria de classes populares), não estamos diante de uma realidade invisível em nosso País: além de legislação, precisamos de políticas de Estado para efetivá-la.

Nosso propósito é colocar o foco das lentes, nesse lugar nada hospitaleiro, mas que pode nos revelar indícios de que nos educamos em todos os espaços onde o convívio se faz necessário, inclusive na prisão.

\section{BRECHAS E POSSIBILIDADES PARA A EDUCAÇÃ̃o NAS PRISÕES}

Apesar dos inúmeros desafios e entraves, existem brechas e possibilidades para a educação nas prisões. Para fins deste artigo, destacamos três dimensões nesse processo: a articulação entre as práticas educativas; a organização curricular flexível e o trabalho interdisciplinar como proposta metodológica e a valorização do trabalho docente. Compreendemos tais dimensões como intimamente imbricadas, sendo imprescindível a valorização do trabalho docente, pelo papel diferenciado e único que o professor tem no contexto prisional, crucial para a construção conjunta de novas formas de organização curricular em que sejam articulados os processos formativos que acontecem dentro e fora da sala de aula.

Na primeira dimensão - articulação entre as práticas educativas - é importante considerar que as demandas de (re)inserção e de (re)socialização não podem ser atribuídas somente à escola e aos professores. Trata-se de um desafio com a convergência de outras práticas sociais que ali acontecem. Entendemos que a escola, as oficinas de trabalho, de artesanato, de informática, de jogos dramáticos, os cultos religiosos, as atividades de lazer, as rodas de leitura, as discussões de documentários, entre outras, se constituem em práticas que educam, uma vez que nelas se estabelecem o convívio, as aprendizagens e o respeito pelo outro. Certamente, uma educação significativa, quer nas prisões ou em outros espaços, deve se constituir de forma articulada, com objetivos delineados pela instituição em um projeto político e pedagógico, de acordo com as suas singularidades.

De igual forma, as ações realizadas entre ministérios, secretarias, universidades, fundações, ONGs, sociedade civil, entre outras, devem estar articuladas. Como sinaliza Ireland,

na perspectiva da aprendizagem e da educação ao longo da vida, dar expressão à educação por uma diversidade de formas não necessariamente restritas à escolaridade [...] e é importante que as atividades educativas desenvolvidas no mesmo espaço sejam articuladas e não fragmentadas (2011, p. 35).

Não se trata de tomar um sujeito a ser atendido por diversas ações isoladas, mas promover um programa educativo integrado, que respeite a singularidade e que faça com que as pessoas se sintam seguras de estar no mundo, saibam fazer escolhas e estejam conscientes de que existem múltiplas formas de se viver. Tais aprendizagens poderão contribuir com o processo de (re)inserção social e na organização de um projeto de vida.

A segunda dimensão - a organização curricular flexivel e o trabalho interdisciplinar - sinaliza a necessidade da existência no território da escola nas prisões, de uma organização curricular flexível e de um trabalho interdisciplinar, que assuma a contradição, uma vez que podem se constituir espaços de diálogo, de luta e de resistência, em busca de uma educação emancipatória construída com os sujeitos e não para os sujeitos. Não é possível, em nosso entender, levar uma proposta de mera transposição de escola convencional, dos currículos, dos materiais, das ferramentas metodológicas para o interior da prisão.

Os desenhos curriculares flexíveis podem ser apropriados aos demais espaços escolares, especialmente aos referentes à Educação de Jovens e Adultos, em função de desejos, necessidades e histórias/trajetórias de vida e à escuta como ferramenta essencial do fazer pedagógico. Não se trata, no entanto, de propor uma educação específica para o contexto prisional, mas também não pode ser a mesma educação que já os excluiu. Concordamos com Pereira, quando afirma que é preciso respeitar as 
singularidades do espaço e "motivar essas pessoas a ponto de ver na educação uma possibilidade de emancipação, ainda na condição de encarceradas" (2011, p.45).

A organização curricular flexível pode sugerir a proposta de uma pedagogia em eixos temáticos, em temas geradores, em projetos com aulas compartilhadas, com organização de atividades individuais e grupais, respeitando os ritmos e níveis de aprendizagem de cada estudante e provocando-os a avançar em suas aprendizagens. Estamos diante de uma instituição que prima pelo rigor às regras de obediência. Para que mais linearidade, mais grades? Para que estabelecer limites em atividades separadas? As rodas de leitura, as atividades de teatro não podem dialogar com as atividades da escola? Os projetos e programas de qualificação para o mundo do trabalho não trazem em seu bojo as aprendizagens da escola? Todos têm conexão com a constituição de novos projetos de vida e precisam ser contemplados e ser objeto de diálogo na sala de aula.

Em tal perspectiva, os currículos das diferentes disciplinas e atividades devem ser pensados em conjunto, como propõem as perspectivas pedagógicas com um propósito epistemológico. No dizer de Frigotto,

A interdisciplinaridade precisa ser compreendida dentro do contexto em que é pensada e produzida: a não atenção ao tecido histórico dentro do qual se produz o conhecimento e as práticas pedagógicas, tem nos levado a tratar a questão da interdisciplinaridade dentro de uma ótica fenomênica, abstrata e arbitrária. Aparece como sendo um recurso didático capaz de integrar, reunir as dimensões particulares dos diferentes campos científicos ou dos diferentes saberes numa totalidade harmônica (2008, p. 52-53).

Esse desenho curricular e metodológico pode garantir a autonomia docente que tem sido duplamente limitada: pelas fontes de conhecimento, que estão determinadas pela cultura dominante, e pelas condições dos contextos específicos de trabalho. Se eles protagonizam o espaço da sala de aula com os estudantes, estão imersos no contexto de uma realidade. Portanto, na escola podem romper as amarras de um tempo linear!

Na terceira dimensão - $A$ valorização do trabalho docente - é preciso considerar que o trabalho dos professores no contexto prisional se dá em um espaço pouco hospitaleiro. Nas regularidades da prisão evidencia-se a figura do professor como ator relevante na construção de espaços onde o aprisionado pode (re)significar o mundo como algo dinâmico e inacabado. Cabe ao professor promover práticas anunciadoras de humanização e produção de subjetividades, e isso implica ou exige a presença de educadores instigadores, inquietos, humildes e persistentes (ONOFRE, 2013).
Importante sinalizar que são ricos os estudos no campo do fazer docente, que indicam caminhos férteis para o repensar da escola e da relevância dos professores para garantir uma educação com qualidade social nestes espaços de privação de liberdade. Estudos como os de Vieira (2008), Nakayama (2011), Menotti (2013), Bessil (2015), Duarte (2017), Barcelos (2017), Lopes (2019) e Cabral (2019) enfatizam que, no dizer dos professores, apesar das limitações dos recursos materiais, dos espaços improvisados, da interferência das normas de segurança na sala de aula, do sofrimento por conta do preconceito que sofrem por parte da sociedade e de colegas que lecionam nas escolas "da rua", dos contratos temporários que geram insegurança e ansiedade, das lacunas na formação, entre outros, exercem a sua função com satisfação, valorizam o processo de escolarização para as pessoas em privação de liberdade, dão sentido à docência, adquirem outras visões de mundo mais humanizadas - a identidade profissional se torna mais presente, pois essas experiências são singulares e únicas.

É preciso apoiar efetivamente os professores que atuam em espaços de privação de liberdade, para que não se sintam sozinhos em uma situação de areia movediça, em que a luta diária para viver diariamente as situaçõeslimite venha a sufocá-los e fazê-los sucumbir. É preciso garantir espaços de diálogo entre os pares e junto à gestão das instituições implicadas, sistemas estaduais de educação e sistema de administração penitenciária, de modo que os professores se sintam representantes de um projeto político pedagógico, e não uma visita inoportuna na prisão.

Na medida em que a voz dos professores encontrar maior eco junto às instituições, podemos ultrapassar uma mera constatação de situações de saturação para potencializar a dimensão política das práticas sociais vinculadas à educação. Trata-se do direito constitucional à educação. Ver os professores como intelectuais transformadores é tornar "o pedagógico mais político e o político mais pedagógico" (GIROUX, 1997, p. 163). Os professores são profissionais da educação, representantes do Estado. Sua atuação se articula a propiciar que aqueles que se encontram em situação de privação de liberdade possam vislumbrar possibilidades de novos projetos de vida.

\section{Conclusõ̂es PROVisórias E PROVOCAÇÕES PARA SEGUIR A CAMINHADA}

“A utopia está lá no horizonte - diz Fernando Birri. Aproximo-me dois passos, ela se afasta dois passos. Caminho dez passos e o horizonte corre dez passos. Por mais que eu caminhe, jamais alcançarei. Para que serve a utopia? Serve para isso: para que eu não deixe de caminhar".

(Eduardo Galeano, 2007) 
Nestas reflexões/provocações finais trazemos uma série de questões que têm determinado entraves que interferem na organização e no funcionamento da escola e indicam as tantas grades que precisam ser rompidas no sistema prisional: por que as unidades prisionais estão superlotadas? Quem vai à escola, apesar dos números elevados de pessoas com escolarização incompleta? Como é feita e quem faz a seleção? Se a educação é um direito estabelecido por lei, por que não é cumprido? Quem deve mover e garantir esse direito? Por que não se pode mexer na rotina da noite em uma unidade prisional? Porque a escola não funciona nos três turnos, mesmo que nos convençam que falta espaço físico - em lugar de quatro salas, teríamos doze, nos três turnos. Mas quem deve assumir essa situação?

Temos nos acomodado a repetir os entraves postos pelo sistema. A propalada (re)educação parece se constituir em uma espécie de educação pelo avesso falta espaço, há poucos funcionários, no período noturno a movimentação para se deslocar dos pavilhões pode desestabilizar a segurança. Até quando a educação escolar, garantida por lei como um direito, será considerada "uma visita inoportuna" nas unidades prisionais? Os entraves precisam ser sinalizados.

Concordamos com Cabral em sua afirmação de que

Não adianta lutar por melhores condições nas instituições prisionais, mas reduzir o número de pessoas que nelas ingressam; apesar da ineficácia do aprisionamento em massa continuamos a afastar as pessoas da sociedade (CABRAL, 2019, p. 85).

Entendemos que o encarceramento em massa é um dos problemas que precisamos enfrentar na construção de uma sociedade democrática e igualitária, para que os direitos humanos sejam uma realidade para a população dentro e fora das prisões. Além disso, o encarceramento em massa é um dos principais motivos da precariedade da oferta educativa nesses contextos. Nesse sentido, a defesa do direito à educação em contextos de privação de liberdade caminha de mãos dadas com a denúncia do encarceramento em massa e todas as violações de direitos humanos a ele associadas.

Embora alguns avanços tenham se constituído no campo normativo, não temos consolidada uma política pública de Educação de Jovens e Adultos nos espaços de privação de liberdade, que permanecem marcados pela marginalização por parte do Estado e da sociedade civil. Tampouco existem políticas públicas que assegurem a formação inicial e continuada dos professores, pois o que tem sustentado o fazer docente são os cursos de pequena duração, ações formativas pontuais promovidas por universidades e secretarias de estado da educação, as trocas entre os professores iniciantes e experientes.
Neste momento histórico brasileiro, em que vivenciamos diariamente situações-limite, é necessário problematizar as sensações de saturação que nos atropelam e potencializar a dimensão política das práticas sociais vinculadas à educação, especialmente para os menos favorecidos, de classes populares, que habitam as prisões. As normativas internacionais e nacionais traçam orientações e recomendações na perspectiva de mudanças de vida que deveriam garantir os direitos humanos de todos, mas a prisão está aí para punir os pobres e pune muito bem. Estamos em busca de ações coletivas que se firmem na convicção de que os nossos impasses no campo político e econômico não serão resolvidos com o discurso da justiça social e de uma sociedade igualitária, mas no respeito aos direitos fundamentais de homens e mulheres que resistem e almejam socialização digna, independente do lugar em que estejam.

\section{REFERÊNCIAS}

ARROYO, Miguel Gonzalez. O saber de si como direito ao conhecimento. In: ARROYO, Miguel Gonzalez. Currículo, território em disputa. Petrópolis: Vozes, 2011. p.279-257. https://doi.org/10.5585/dialogian15.3949

BARCELOS, Clayton da Silva. Educação escolar na prisão: os significados e sentidos das professoras que atuam em unidades penais de Corumbá, Mato Grosso do Sul. 2017. 167 f. Dissertação (Mestrado em Educação) - Universidade Federal de Mato Grosso do Sul - MS. 2017. https://doi, org/10.20873/uft.2525-4863.2018v3n2p633

BESSIL, Marcela Haupt. A prática docente de educação de jovens e adultos no sistema prisional: um estudo da psicodinâmica do trabalho. 2015. 217 f. Dissertação (Mestrado em Educação) - Universidade Federal do Rio Grande do Sul, Porto Alegre. 2015. https://doi.org/10.29289/2 59453942018v28s1059

BRASIL. Lei no 7.210, de 11 de julho de 1984. Institui a Lei de Execução Penal. Disponível em: http://www. planalto.gov.br/ccivil_03/LEIS/L7210.htm. Acesso em: 20 mar. 2019.

BRASIL. [Contituição (1988)]. Constituição da República Federativa do Brasil de 1988. Disponível em: http://www. planalto.gov.br/ccivil_03/constituicao/constituicaocompilado. htm. Acesso em: 20 mar. 2019. https://doi.org/10.11606/ d.2.2010.tde-13122010-160747

BRASIL. Decreto no 7.626, de 24 de novembro de 2011. Institui o Plano Estratégico de Educação no âmbito do Sistema Prisional. Disponível em: http://portal.mec. gov.br/index.php?option=com_docman\&view=download\& alias=10027-decreto-7626-24-novembro-2011\&category_ slug=fevereiro-2012-pdf\&Itemid=30192. Acesso em: 23 mar. 2019. https://doi.org/10.14393/che-v17n32018-16 
BRASIL. Levantamento Nacional de Informações Penitenciárias - atualização junho de 2016. Brasília: DEPEN, MJ, 2017. Disponível em: http://depen.gov.br/ DEPEN/noticias-1/noticias/infopen-levantamento-nacionalde-informacoes-penitenciarias-2016/relatorio_2016_22111. pdf. Acesso em: 20 mar. 2019 https://doi.org/10.17012/ entac2014.411

BRASIL/CNE/CEB. Resolução no 2, de 19 de maio de 2010. Dispõe sobre as Diretrizes Nacionais para a oferta de educação para jovens e adultos em situação de privação de liberdade nos estabelecimentos penais. Disponível em: http://portal.mec.gov.br/index.php?option=com docman\&view $=$ download\&alias $=5142$-rceb00210\&category_slug=maio-2010-pdf\&Itemid=30192. Acesso em: 23 mar. 2019. https://doi.org/10.1590/cc010132622015723761

CABRAL, Paula. A EJA nos espaços de privação e restrição de liberdade: as apropriações das diretrizes da UNESCO no redirecionamento do trabalho dos professores. 2019. Tese (Doutorado em Educação) - Universidade Federal de Santa Catarina, Florianópolis. 2019. https://doi. org/10.17533/udea.efyd.v33n2a05

CAMPOS, Aline. Educação, escola e prisão: o espaço de voz de educandos do Centro de Ressocialização de Rio Claro/ SP. 2015. Universidade Federal de São Carlos - UFSCar, São Carlos, 2015. https://doi.org/10.20396/ccfenf1201839

COSTA, Antonio Carlos Gomes da (coord.). Socioeducação: Estrutura e Funcionamento da Comunidade Educativa. Brasília: Secretaria Especial dos Direitos Humanos, 2006. $156 \mathrm{p}$.

DE MAYER, Marc. A educação na prisão não é uma mera atividade. Educação \& Realidade, Porto Alegre, v. 38, n. 1, p. 33-49, jan./mar. 2013. https://doi.org/10.1590/s217562362013000100004

DEPEN. Levantamento Nacional de Informações Penitenciárias - junho de 2016. Brasília: DEPEN, 2017.

DUARTE, Alisson José Oliveira. O processo de constituição da identidade profissional de professores da educação carcerária. 2017. 149 f. Dissertação (Mestrado em Educação) - Universidade Federal do Triângulo Mineiro - Minas Gerais. 2017. https://doi.org/10.20873/uft.2525-4863.2017v2n1p411

FREIRE, Paulo. Educação na Cidade. São Paulo: Cortez, 1991.

FREIRE, Paulo. Política e Educação. São Paulo: Cortez, 1993.

FREIRE, Paulo. Pedagogia do Oprimido. 42. ed. Rio de Janeiro: Paz e Terra, 2005.

FRIGOTTO, Gaudêncio. A interdisciplinaridade como necessidade e como problema nas Ciências Sociais. Ideação: Revista do Centro de Educação e Letras, Foz do Iguaçu, v. 10, n. 1, p. 41-62, jan./jun. 2008.
GALEANO, Eduardo. As palavras andantes. Porto Alegre: L\&PM, 2007.

GIROUX, Henry. Professores como intelectuais transformadores. In: GIROUX, Henry. Os professores como intelectuais: rumo a uma pedagogia crítica da educação. Porto Alegre: Artes Médicas, 1997. p. 157-163. https://doi. org/10.24824/978854442332.5

GOFFMAN, Erving. Manicômios, Prisões e Conventos. São Paulo: Perspectiva, 2015. https://doi.org/10.20396/rho. v9i33.8639569

IRELAND, Timothy Denis. Educação em prisões no Brasil: direito, contradições e desafios. Em Aberto, Brasília, DF, v. 24, n. 86, p. 19-39, 2011.

LOPES, Cloris Violeta Alves. Do ser ao tornar-se professor nas escolas dos espaços de privação de liberdade. 2019. Tese (Doutorado em Educação) - Universidade Federal de São Carlos, São Carlos. 2019. https://doi.org/10.5327/ z1679443520190277

MARQUES, Larissa Rabêlo. Atividades experimentais no Ensino de Química: uma proposta didática no contexto da socioeducação. 2016. 155 f., il. Dissertação (Mestrado Profissionalizante em Ensino de Ciências) - Universidade de Brasília, Brasília, 2016. https://doi.org/10.4322/2526-4664.076

MENOTTI, Camila Cardoso. O exercício da docência entre as grades: reflexões sobre a prática de educadores do sistema prisional do estado de São Paulo. 2013. 129f. Dissertação (Mestrado em Educação) - Universidade Federal de São Carlos, São Carlos. 2013. https://doi.org/10.1590/s223689062011000200005

NAKAYAMA, Andréa Rettig. O Trabalho de professores/ as em um espaço de privação de liberdade: necessidades de formação continuada. 2011. Dissertação (Mestrado em Educação) - Programa de Pós-Graduação em Educação, Universidade Federal de Santa Catarina, Florianópolis. 2011. https://doi.org/10.1590/s2175-62362013000100010

OLIVEIRA JUNIOR, Dalmir Franklin de. Projeto banda liberdade: a prioridade absoluta nas medidas socioeducativas. 2016. 202 f. Dissertação (Mestrado em Direito) -

Universidade de Passo Fundo, Passo Fundo, 2016. https://doi. org/10.29289/2594539420190000424

ONOFRE, Elenice Maria Cammarosano. Educação escolar na prisão: controvérsias e caminhos de enfrentamento e superação da cilada. In: LOURENÇO, Arlindo da Silva; ONOFRE, Elenice Maria Cammarosano (org.). O espaço da prisão e suas práticas educativas: enfoques e perspectivas contemporâneas. 1. ed. São Carlos: EdUFSCar, 2011. v. 1. p. 267-285. https://doi.org/10.7476/9788576002963

ONOFRE, Elenice Maria Cammarosano. Políticas de formação de educadores para os espaços de restrição e de privação de liberdade. Revista Eletrônica de Educação, São Carlos, v. 7, p. 137-158, 2013. https://doi.org/10.18788/22371451/rle.v3n6p5-18 
ONOFRE, Elenice Maria Cammarosano. A prisão: instituição educativa? Cadernos CEDES, Campinas, v. 36, p. 43-59, 2016. https://doi.org/10.1590/cc0101-32622016162569

PEREIRA, A. A educação-pedagogia no cárcere no contexto da pedagogia social: definições conceituais e epistemológicas. Revista Educação Popular, Uberlândia, v. 10, p. 38-55, jan./ dez. 2011.

PÉREZ GÓMEZ, Angel I. As funções sociais da escola: da reprodução à reconstrução crítica do conhecimento e da experiência. In: GIMENO SACRISTÁN, José; PÉREZ GÓMEZ, Angel I. Compreender e transformar o ensino. 4. ed. Porto Alegre: ARTMED, 2000. p.13-26.

PÉREZ GÓMEZ, Angel I. Educação na era digital: a escola educativa. Trad. Marisa Guedes. Porto Alegre: Penso, 2015.

PESSANO, Edward Frederico Castro. O rio Uruguai como estratégia de contextualização do ensino em uma escola com restrição de liberdade. 2015. 290 f. Tese (Doutorado em Educação em Ciências) - Universidade Federal de Santa Maria, Santa Maria, 2015. https://doi.org/10.14483/udistrital. jour.gdla.2015.1.a05

PRADO, Alice Silva do. Educação nas prisões: desafios e possibilidades do ensino praticado nas unidades prisionais de Manaus. 2015. 107 f. Dissertação (Mestrado em Sociologia) Universidade Federal do Amazonas - UFAM, Manaus, 2015. https://doi.org/10.21041/conpat2019/v2pat298

SANTANA, Aline Neves Vieira de. Contribuições do ensino de ciências no centro de atendimento socioeducativo de Goiânia. 2013. 123 f. Dissertação (Mestrado em educação em Ciências e Matemática) - Universidade Federal de Goiás, Goiânia, 2013. https://doi.org/10.17140/oroj-2-111

SAVIANI, Demerval. Escola e Democracia. 32. ed. Campinas: Autores Associados, 1999.

SCHOLZ, René Gomes. Educomunicação \& socioeducação: a implantação e desenvolvimento da rádio escola São Francisco. 2017. 167 f. Dissertação (Mestrado em Educação) - Universidade Federal do Paraná, Curitiba, 2017.

SILVA, Lucas Lourenço. O direito à educação escolar prisional: uma realidade entre grades. 2017. $165 \mathrm{f}$. Dissertação. (Mestrado em Educação) - Pontifícia Universidade Católica de Goiás - PUC Goiás, Goiânia, 2017. https://doi.org/10.14295/2596-2221.xviceel.2018.185

SILVA, Petronilha Beatriz Gonçalves e. Educação e identidade dos negros trabalhadores rurais do Limoeiro. 1987. 293 f. Tese. (Doutorado em Educação) - Universidade Federal do Rio grande do Sul, Porto Alegre, 1987. https://doi. org/10.29289/259453942018v28s 1059

SILVA, Thayla Fernanda Souza e. Narrativas de vida e formação da pessoa privada de liberdade: sentidos (re)construídos na/pela experiência. 2019. 196 f. Dissertação (Mestrado em Educação) - Universidade Federal de
Mato Grosso, Cuiabá, 2019. https://doi.org/10.5327/ z201700010017rbm

VIEIRA, Elizabeth de Lima Gil. Trabalho docente: de portas abertas para o cotidiano de uma escola prisional. 2008. 136 f. Dissertação (Mestrado em Educação) - Pontifícia Universidade Católica do Rio de Janeiro, Rio de Janeiro, 2008. https://doi.org/10.17771/pucrio.acad.12527

WACQUANT, Loïc. As Prisões da Miséria. 2. ed. Rio de Janeiro: Zahar, 2011.

Recebido em: 30/3/2019.

Aprovado em: 17/9/2019.

Publicado em: 20/12/2019.

Endereço para correspondência:

Elenice Maria Cammarosano Onofre

Rua 28 de setembro, 2293, Ap. 42 - Centro

13560-270, São Carlos, São Paulo, Brasil

\section{Autoras:}

Elenice Maria Cammarosano Onofre

Doutorado em Educação Escolar, Universidade Estadual Paulista, UNESP, Araraquara, SP. Professora da Universidade Federal de São Carlos (UFSCAR), São Carlos, SP, Brasil.

Orcid: http://orcid.org/0000-0002-3623-4728

E-mail:1inocam@uol.com.br

Jarina Rodrigues Fernandes

Doutorado em Educação: Currículo, Pontifícia Universidade Católica de São Paulo (PUC/SP), São Paulo, SP. Professora da Universidade Federal de São Carlos (UFSCAR), São Carlos, SP, Brasil.

Orcid: http://orcid.org/0000-0001-8028-467X

E-mail: jarina.fernandes@ufscar.br

Endereço: Rua Antonio Rodrigues Cajado, 1506, Ap. 102

13560-291, São Carlos, São Paulo, Brasil

Ana Claudia Ferreira Godinho

Doutorado em Educação, Universidade do Vale do Rio dos Sinos (UNISINOS), São Leopoldo, RS. Professora da Universidade Federal do Rio Grande do Sul (UFRGS), Porto Alegre, RS, Brasil.

Orcid: http://orcid.org/0000-0002-4655-5875

E-mail: anaclaudia.godinho@gmail.com

Rua dos Andradas, 777, Ap. 71 - Centro Histórico

900020-003, Porto Alegre, RS, Brasil 